\title{
Effect of drug incorporation technique and polymer combination on the performance of biopolymeric antifungal buccal films
}

\author{
G. Tejada ${ }^{\mathrm{a}}$, M.C. Lamas ${ }^{\mathrm{a}, \mathrm{b}}$, L. Svetaz ${ }^{\mathrm{c}}$, C.J. Salomón ${ }^{\mathrm{a}, \mathrm{b}}$, V.A. Alvarez ${ }^{\mathrm{d}}$, D. Leonardi ${ }^{\mathrm{a}, \mathrm{b}, *}$ \\ a IQUIR-CONICET, Suipacha 570, 2000 Rosario, Argentina \\ b Área Técnica Farmacéutica, Departamento Farmacia, Facultad de Ciencias Bioquímicas y Farmacéuticas, Universidad Nacional de Rosario, Suipacha 570, 2000 Rosario, \\ Argentina \\ c Área Farmacognosia, Departamento Química Orgánica, Facultad de Ciencias Bioquímicas y Farmacéuticas, Universidad Nacional de Rosario, Suipacha 570, 2000 \\ Rosario, Argentina \\ d Grupo de Materiales Compuestos Termoplásticos (CoMP), Instituto de Investigaciones en Ciencia y Tecnología de Materiales (INTEMA, CONICET-UNMdP), Av. Colón \\ 10890, Mar del Plata 7600, Argentina
}

\section{A R T I C L E I N F O}

\section{Keywords:}

Films

Solubilized drug

Suspended drug

Mechanical properties

Antifungal activity

\begin{abstract}
A B S T R A C T
Numerous films with a dissolved or dispersed active principle within a polymeric matrix have been described in literature. However, the incorporation of solid crystals into the films may influence several relevant properties. Additionally, it has been reported that different polymeric matrices lead to films presenting a different performance. The aim of this work was to evaluate the effect of the combination of chitosan with carrageenan ( $\kappa-$, $\lambda$-, and $1-$ ) as matrices, and of the miconazole nitrate incorporation method, on the films behavior. Mechanical properties, drug release and antifungal activity were evaluated. The state of the drug in the films was analyzed by different techniques. Films showed a homogeneous surface and a thermal protective effect on the drug. The combination of chitosan and $\lambda$-carrageenan leads to films with the highest values of tensile and mucoadhesive strength. Films with solubilized drug displayed slightly higher elongation at break, tensile and mucoadhesive strength and faster drug release than those with suspended miconazole nitrate. However, no differences were found regarding the antifungal activity of the different formulations including time-to-kill curves.
\end{abstract}

\section{Introduction}

Candidiasis is probably the most prevalent opportunistic fungal infection of the oral cavity. Its incidence varies depending on age and certain predisposing factors, being immunocompromised patients the most affected ones (Spampinato and Leonardi, 2013; Van Roey et al., 2004). Several antifungal drugs used for the treatment of the buccal infections are administered orally and topically. Topical agents, applied directly to the infected area, proved to be quite effective to treat superficial candidiasis while systemic chemotherapeutic drugs are recommended in the management of invasive fungal infections that cannot be treated locally (Spampinato and Leonardi, 2013). In recent years, a remarkable interest has been focussed on the topical route for the treatment of fungal pathologies due to the specific physiological characteristics of the oral cavity (Morales and McConville, 2011; Van Roey et al., 2004). The treatment of oral candidiasis usually requires long-term administration of antifungal agents. The success of the treatment against this oral pathology depends, among other factors, on the pharmaceutical dosage form used for its administration in the oral cavity. An ideal dosage form should be able to maintain the drug concentration higher than the minimal inhibitory concentration in the salivary fluid, over an extended period, reducing the dosage frequency. Among the different formulations, which may be applied in mouth are buccal films. Buccal films offer advantages over adhesive tablets in terms of flexibility and comfort (Morales and McConville, 2011). Moreover, buccal films are also suitable for protecting wound surfaces, which is important when the infection produces ulcerative lesions (Llabot et al., 2007). An ideal buccal film should be flexible, elastic, and soft but adequately resistant in order to prevent breakage due to stress from oral activities (Tejada et al., 2017). Moreover, it must also possess good bioadhesive strength so that it can be retained in the mouth for long periods (Tejada et al., 2017). In addition, polymeric films provide distinct advantages over other oral formulations including acceptability and compliance among geriatric and pediatric patients (SievensFigueroa et al., 2012), and also, exhibit manufacturing advantages including continuous manufacturing capabilities (Dixit and Puthli, 2009; Sievens-Figueroa et al., 2012). The characteristics of buccal polymeric films are highly dependent on the type and concentration of the

\footnotetext{
* Corresponding author at: Facultad de Ciencias Bioquímicas y Farmacéuticas, Universidad Nacional de Rosario, Suipacha 531, 24 (2000) Rosario, Argentina.

E-mail address: leonardi@iquir-conicet.gov.ar (D. Leonardi).
} 
B

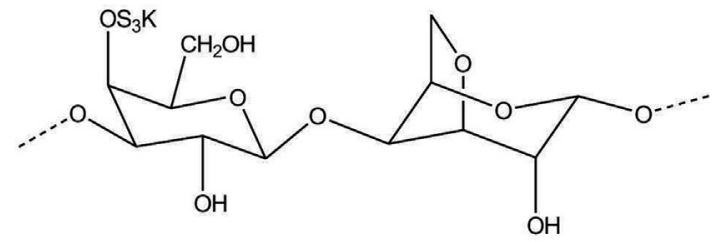

C

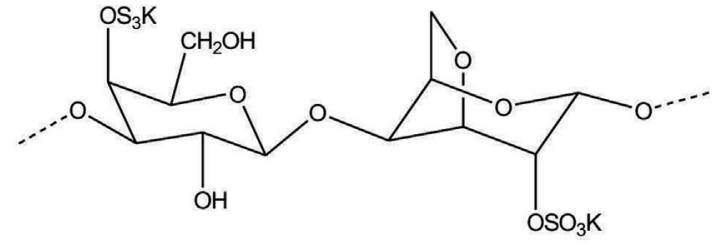

D

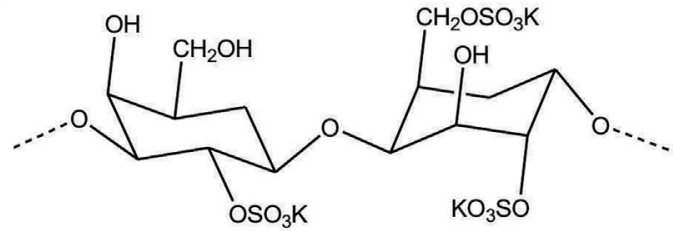

Fig. 1. Chemical structures of different polymers employed in the development of polymeric films. A: CH, B: $\kappa-C, C:$ i-C and D: $\lambda$-C.

polymers used. Furthermore, several polymers such as chitosan $(\mathrm{CH})$, kappa-carragenan $(\mathrm{k}-\mathrm{C})$, lambda-carragenan $(\lambda-\mathrm{C})$ and iota-carragenan (1-C) (Hambleton et al., 2009; Kalsoom Khan et al., 2017; Karbowiak et al., 2006; Kaur and Kaur, 2012; Khajuria et al., 2018; Kianfar et al., 2012; Lima et al., 2013; Shahbazi et al., 2016) were used to develop drug delivery systems,. CH (Fig. 1A), a polysaccharide obtained from the deacetylation of chitin, is a well known cationic biodegradable and biocompatible natural polymer which show film forming capacity and mucoadhesive properties due to the interaction between its positively charged amino groups and negatively charged sialic acid residues in mucus (Tang et al., 2014). Additionally, CH cations exhibit good affinity to form polyelectrolyte complexes with anionic biopolymers.

Carrageenans are water-soluble galactose polymers extracted from red seaweed, which are extensively used in the food and pharmaceutical industries as gelling and stabilizing agents (Cha et al., 2002). The isomers of carrageenan ( $\kappa-,-1$-, and $\lambda$-carrageenan) differ in the number and position of the ester sulfate groups on the galactose units: kappa has one, iota has two, and lambda has three (Kalsoom Khan et al., 2017) (Fig. 1B-D). It has also been reported that the gelling power of $\kappa$-and $1-$ carrageenans impart excellent film-forming properties (Park et al., 2001). Even though the interest in pharmaceutical films has increased according to publications in recent years (Chonkar et al., 2016; Krampe et al., 2016; Montenegro-Nicolini and Morales, 2017; Morales and Brayden, 2017; Park et al., 2001; Real et al., 2013; Trastullo et al., 2016; Woertz and Kleinebudde, 2015), more research is needed in order to overcome potential limitations and increase general patient acceptance (Sievens-Figueroa et al., 2012). Regarding the films, numerous systems have been described in literature where the active ingredient have been dissolved or dispersed within the polymeric material (ElKamel et al., 2007; Gallagher and Corrigan, 2000; Kolakovic et al., 2012; Perugini et al., 2003). While water-soluble drugs exist in the dissolved state or as a solid solution, water-insoluble drugs should be homogenously distributed in a film formulation in order to have acceptable drug content uniformity (Sievens-Figueroa et al., 2012). Miconazole nitrate $(\mathrm{MN})$ is an azole antifungal agent currently available to treat mucosal or systemic infections caused by Candida spp (Spampinato and Leonardi, 2013). The Biopharmaceutics classification system classified $\mathrm{MN}$ as Class II (drugs having dissolution-limited bioavailability because of their poor water solubility). This poor water solubility may hinder the formulation of buccal films with dissolved MN. However, the incorporation of solid MN crystals into the films, even in very small sizes, may influence properties like mechanical strength, adhesiveness, homogeneity, drug release, and rate of antifungal activity. To our knowledge, there is no previous research studying the influence of drug incorporation on the final characteristics of polymeric films and, in addition, formulation of buccal films containing $\mathrm{CH}$ in combination with $\kappa_{-}, \lambda_{-}$, and $\mathrm{l}$-carrageenan to deliver $\mathrm{MN}$, has not been previously investigated. Thus, the aim of this work was to evaluate whether the combination of those biopolymers and the manufacturing techniques applied to formulate MN buccal films would modify its physicochemical properties. Mechanical properties, drug release, and antifungal activity, were then evaluated. Additionally, the drug solid state in the films was thoroughly analyzed by X-ray diffraction, thermogravimetric analysis, differential thermogravimetric analysis, and differential scanning calorimetry.

\section{Materials and methods}

\subsection{Materials}

CH (230 KDa average molecular weight and $80.6 \%$ of N-deacetylation) was supplied by Aldrich Chemical Co. (Milwaukee, WI, USA), Food-grade $\kappa, l$, and $\lambda$-carrageenan samples were kindly donated by FMC BioPolymer (Philadelphia, PA), and MN pharmaceutical grade was purchased from Parafarm, (Buenos Aires, Argentina). All other chemicals were of analytical grade.

\subsection{Film preparation}

Polymeric films were prepared by the solvent casting method. The formulated films are described in Table 1. Briefly, $\mathrm{CH}$ solution (3\% w/ v) was prepared dispersing $\mathrm{CH}$ in a solution of $10 \% \mathrm{v} / \mathrm{v}$ lactic acid $(\mathrm{pH}=2.67$ ), polysorbate 80 (tween 80 ) $0.1 \% \mathrm{v} / \mathrm{v}$ was added to this solution in order to obtain a homogeneous dispersion of the final suspension (when polymers and drugs are mixed). In parallel, aqueous acid solutions $(0.15 \% \mathrm{v} / \mathrm{v}$ lactic acid) of $\kappa, \mathrm{l}$, or $\lambda$-carrageenan $(1 \% \mathrm{w} / \mathrm{v})$, were prepared, stirred overnight, and filtered through Miracloth ${ }^{\circledR}$ (Calbiochem-Novabiochem Corp., San Diego, CA). Each polymeric 
Table 1

Films composition.

\begin{tabular}{|c|c|c|c|c|c|c|}
\hline Number & Formulation & $\begin{array}{l}\mathrm{CH}(\% \\
\mathrm{w} / \mathrm{w})\end{array}$ & $\begin{array}{l}\text { i-C (\% } \\
w / w)\end{array}$ & $\begin{array}{l}\kappa-C(\% \\
w / w)\end{array}$ & $\begin{array}{l}\lambda-\mathrm{C}(\% \\
\mathrm{w} / \mathrm{w})\end{array}$ & MN added \\
\hline 1 & $\mathrm{CH}$ & 100 & 0 & - & - & - \\
\hline 2 & $1-C$ & 0 & 100 & - & - & - \\
\hline 3 & $\mathrm{CH}-\mathrm{-}-\mathrm{C}$ & 75 & 25 & - & - & - \\
\hline 4 & $\kappa-\mathrm{C}$ & 0 & - & 100 & - & - \\
\hline 5 & СН-к-C & 75 & - & 25 & - & - \\
\hline 6 & $\lambda-C$ & 0 & - & 100 & - & - \\
\hline 7 & $\mathrm{CH}-\lambda-\mathrm{C}$ & 75 & - & 25 & - & - \\
\hline 8 & CH-MN-SUS & 100 & 0 & - & - & Suspended \\
\hline 9 & CH-ı-C-MN-SUS & 75 & 25 & - & - & Suspended \\
\hline 10 & 1-C-MN-SUS & 0 & 100 & - & - & Suspended \\
\hline 11 & к-C-MN-SUS & 0 & - & 100 & - & Suspended \\
\hline 13 & СH-к-C-MN-SUS & 75 & - & 25 & - & Suspended \\
\hline 12 & $\lambda$-C-MN-SUS & 0 & - & 100 & - & Suspended \\
\hline 14 & $\mathrm{CH}-\lambda-\mathrm{C}-\mathrm{MN}-\mathrm{SUS}$ & 75 & - & 25 & - & Suspended \\
\hline 15 & CH-MN-SOL & 100 & 0 & - & - & Solubilized \\
\hline 16 & CH-ı-C-MN-SOL & 75 & 25 & - & - & Solubilized \\
\hline 17 & 1-C-MN-SOL & 0 & 100 & - & - & Solubilized \\
\hline 18 & к-C-MN-SOL & 0 & - & 100 & - & Solubilized \\
\hline 19 & CH-к-C-MN-SOL & 75 & - & 25 & - & Solubilized \\
\hline 20 & $\lambda$-C-MN-SOL & 0 & - & 100 & - & Solubilized \\
\hline 21 & $\mathrm{CH}-\lambda-\mathrm{C}-\mathrm{MN}-\mathrm{SOL}$ & 75 & - & 25 & - & Solubilized \\
\hline
\end{tabular}

solution was then dripped over $\mathrm{CH}$ solution under magnetic stirring (Boecco stirrer, Germany) at $80{ }^{\circ} \mathrm{C}$ to avoid precipitation. After that, PEG 400, employed as a plasticizer $(30 \% \mathrm{w} / \mathrm{w})$, was then added and stirred at $200 \mathrm{rpm}$ for $2 \mathrm{~h}$. Finally, MN ( $8 \% \mathrm{w} / \mathrm{w})$ was added by sieving $(840 \mu \mathrm{m})$ to the mixture and stirred for $2 \mathrm{~min}$ (Table 1, formulations $8-14)$. The suspensions were cast on $9 \mathrm{~cm}$ diameter Petri dishes and dried $\left(48 \mathrm{~h}\right.$ at $40{ }^{\circ} \mathrm{C}$, and $58 \%$ relative humidity (RH)). Dried films were removed from the Petri dishes and conditioned in a chamber $(72 \mathrm{~h}$ at $25^{\circ} \mathrm{C}$ and $\left.58 \% \mathrm{RH}\right)$. A similar procedure was performed but this time MN was solubilized in PEG 400 employed as a plasticizer (stirring at $200 \mathrm{rmp}$ for $2 \mathrm{~h}$ ), and added to the polymeric solutions (Table 1 , formulations 15-21). The films used in the different tests were selected based on the lack of physical defects such as holes, cracks, or bubbles.

\subsubsection{Film characterization}

\subsubsection{Folding endurance, film thickness, and mechanical properties}

2.2.1.1.1. Folding and thickness. Folding endurance was determined by repeatedly folding the films at the same place until they broke or were folded 300 times (Avachat et al., 2013). The thickness of each film was obtained with a digital micrometer (Schwyz, China). Ten measurements were made around and in the center of each film (Libio et al., 2016).

2.2.1.1.2. Mechanical properties. A texturometer (Mecmesin Multitest 2.5d, Mecmesin, Sterling, VA, U.S.A.) with a $10 \mathrm{~N}$ load cell was used to analyze the mechanical strength of the films, which had previously been conditioned $\left(24 \mathrm{~h}\right.$ at $25{ }^{\circ} \mathrm{C}$ and $\left.58 \% \mathrm{RH}\right)$ and cut into strips ( $7 \mathrm{~mm}$ wide and $60 \mathrm{~mm}$ long) to evaluate tensile properties (Tejada et al., 2017). Each sample was clamped between tensile grips, the distance between the grips was $30 \mathrm{~mm}$ and the crosshead speed was $0.05 \mathrm{~mm} / \mathrm{s}$. The parameters obtained from stress/strain curves were tensile strength (TS), and elongation at break (E). TS is a measure of the maximal force per original cross-sectional area that the film could support before breaking, whereas $\mathrm{E}$ was determined as the percentage of change in the length of each sample with respect to the initial distance between grips, and it estimates the capacity of the film to extend before breaking. For each film, three replicate measurements were performed.

2.2.1.2. In vitro mucoadhesive strength. A texturometer (Mecmesin Multitest 2.5d, Mecmesin, Sterling, VA, U.S.A.) was employed to analyze the mucoadhesive strength of each film. The force required to detach each formulation from a disc of porcine gum (obtained from
"Paladini" slaughterhouse, V.G. Galvez, Argentina) was measured. A portion of each film ( $2.5 \mathrm{~cm}$ diameter) was added to the upper end of the cylindrical probe and gum discs (obtained by punch biopsy and hydrated with $0.5 \mathrm{~mL}$ artificial saliva for $2 \mathrm{~min}$ ) were horizontally attached to the lower end of the cylindrical probe by using double-sided adhesive tape. Artificial saliva consisted of phosphate buffer saline solution $\left(2.38 \mathrm{~g} \mathrm{Na}_{2} \mathrm{HPO}_{4}, 0.19 \mathrm{~g} \mathrm{KH}_{2} \mathrm{PO}_{4}\right.$ and $8.00 \mathrm{~g} \mathrm{NaCl}$ per liter of distilled water adjusted with phosphoric acid to $\mathrm{pH}$ 6.75) (Borges et al., 2015; Peh and Wong, 1999). Each film remained in contact with the gum for $1 \mathrm{~min}$ and it was then moved upwards at a constant speed $(1.0 \mathrm{~mm} / \mathrm{min})$. The test was carried out in triplicate. The force required to detach each film from the gum disc was determined from the resulting force/time plot. (Eouani et al., 2001).

2.2.1.3. Swelling index. An accurately weighed portion of the films ( $2.5 \mathrm{~cm}$ diameter) was immersed in $0.5 \mathrm{~mL}$ of artificial saliva at $37^{\circ} \mathrm{C}$ (Giovino et al., 2013). At predetermined time intervals, the films were carefully removed, and the excess adhering moisture was gently blotted off and weighed. After that, $0.5 \mathrm{~mL}$ of artificial saliva was added again. The swelling index (SI) was calculated using the weights of dried $\left(\mathrm{W}_{0}\right)$ and swollen $\left(\mathrm{W}_{\mathrm{t}}\right)$ films (Equation (1). The test was carried out in triplicate (Libio et al., 2016).

$\mathrm{SI}=\mathrm{W}_{\mathrm{t}}-\mathrm{W}_{0} / \mathrm{W}_{0}$

2.2.1.4. Scanning electron microscopy. The morphology of raw materials and films was analyzed using a scanning electron microscopy (SEM, AMR 1000, Leitz, Wetzlar, Germany). A conductive and double-sided adhesive was employed to mount the film samples on an aluminum sample support. Samples were coated with a fine gold layer ( $15 \mathrm{~min}$ at 70-80 mTorr) in order to make them conductive before obtaining micrographs. Examinations were carried out using an accelerating voltage of $20 \mathrm{kV}$ and magnifications of $200 \times, 500 \times$ and $1000 \times$.

2.2.1.5. X-Ray diffraction. An automated X'Pert Phillips MPD difractometer (Eindhoven, The Netherlands) was employed to the experiments. Data collection was carried out in transmission mode. Xray diffraction patterns were recorded using $\mathrm{CuKa}$ radiation $\left(\lambda=1.540562 \AA\right.$ ), $40 \mathrm{kV}$ (voltage), $20 \mathrm{~mA}$ (current) and $0.02^{\circ}$ (steps) in the interval $2 \Theta=10^{\circ}-50^{\circ}$. Parallel beam geometry, by means of an $\mathrm{X}$-ray lens and a graphite monocromator placed before the detector window, was employed to assure low peak broadening and background. Data acquisition and evaluation were performed with the Stoe VisualXpow package, Version 2.75 (Germany).

2.2.1.6. Thermal analysis. Thermal gravimetric analysis (TGA) was performed with a TG HI-Res thermal analyzer (TA Instruments) at a heating rate of $10^{\circ} \mathrm{C} / \mathrm{min}$ from room temperature to $650{ }^{\circ} \mathrm{C}$ in air flow.

Differential Scanning Calorimetry (DSC) tests were performed in a Linseis DSC PT1000, from 25 to $250{ }^{\circ} \mathrm{C}$ at a heating rate of $10^{\circ} \mathrm{C} / \mathrm{min}$ under nitrogen.

2.2.1.7. Dissolution studies. Dissolution studies were performed in $900 \mathrm{~mL}$ of distilled water containing $1 \% \mathrm{v} / \mathrm{v}$ PEG 400 at $37^{\circ} \mathrm{C}$, using a USP XXIV apparatus II (Hanson Research, SR8 8-Flask Bath, Ontario, Canada) with paddles rotating at $50 \mathrm{rpm}$. MN $80 \mathrm{mg}$ was dispersed in the dissolution medium while different films (containing $80 \mathrm{mg} \mathrm{MN}$ ) were fixed to the central shaft using cyanoacrylate adhesive. Three samples of $5 \mathrm{~mL}$ each were taken using a $0.45 \mu \mathrm{m}$ filter, at different times: $0,10,20,30,40,50,60,90,120,180,240,300$ and $360 \mathrm{~min}$. The amount of MN released was determined by UV spectrometry using the drug absorption band $(272 \mathrm{~nm})$. Dissolution studies were also performed with unloaded films and each absorbance obtained at different times was used as blank. An equal volume of the dissolution medium was added after each sample extraction to maintain a constant volume. 
2.2.1.8. Halo zone test. The test was carried out on Agar plates (150 mm diameter) containing Mueller-Hinton agar, supplemented with $2 \%$ glucose $(2 \mathrm{~g} / 100 \mathrm{~mL})$ and $0.5 \mu \mathrm{m} / \mathrm{mL}$ methylene blue (MB), at a depth of $4.0 \mathrm{~mm}$ following the guidelines of the disk diffusion method described in CLSI document M44-A2 (Clinical and Laboratory Standards Institute, 2008). Candida albicans ATCC 10231, provided by American Type Culture Collection (ATCC), Rockville, MD, USA. Prior to each experiment, the isolate was aerobically cultured at $35^{\circ} \mathrm{C}$ for $24 \mathrm{~h}$. Cell suspension inocula were obtained according to the reported procedures and adjusted in sterile distilled water to 0.5 McFarland standard (approximately $1-5 \cdot 10^{6} \mathrm{CFU} / \mathrm{mL}$ ) (Postigo et al., 2017). The agar surface was inoculated by dipping sterile cotton swabs into a cell suspension and by streaking the plate surface in three directions. The plate was allowed to dry for $20 \mathrm{~min}$, and the films were then placed onto the surface of agar, and incubated in air at $28^{\circ} \mathrm{C}$ for $24 \mathrm{~h}$. The halo zone of complete inhibition was determined using a caliper and the mean value for each organism was recorded (Wang et al., 2015).

2.2.1.9. Time-to-kill analysis. The time-to-kill curves were performed to assess the exposure time required to kill a standardized C. albicans inoculum. The test organisms $\left(10 \mathrm{~mL}\right.$, approximately $\left.10^{4} \mathrm{CFU} / \mathrm{ml}\right)$ were incubated with agitation in Sabouraud dextrose broth medium containing different films $(2.5 \mathrm{~mm})$ or an equivalent $\mathrm{MN}$ content. Aliquots of control and samples were taken and diluted at $0,15,30$, $45,60,90,120,150 \mathrm{~min}$, and $24 \mathrm{~h}$, and the microorganisms were counted by spreading each sample onto a Sabouraud dextrose agar plate. The plates were incubated for $24 \mathrm{~h}$ and the viable colonies were evaluated. The kill curves were constructed by plotting the $\mathrm{CFU} / \mathrm{ml}$ surviving at each time point in the presence and absence of the films or MN raw material (Tonglairoum et al., 2015a,b).

2.2.1.10. Statistical analysis. Analysis of variance was used, and when the effect of the factors was significant, the Tukey multiple ranks honestly significant difference test was applied (GraphPad Prism 5). Differences at $\mathrm{p}<0.05$ were considered significant.

\section{Results and discussion}

\subsection{Films' thickness folding endurance and mechanical properties}

Films based only on $1-\mathrm{C}$, $\mathrm{\kappa}-\mathrm{C}$ and $\lambda-\mathrm{C}$ were unable to be analyzed. Films based only on $\kappa-C$ were brittle while films based on $1-C$ and $\lambda-C$ were soft, elastic and presented high adhesive behavior to the Petri dishes, and therefore these formulations were disposable.

Thicknesses of different formulations (loaded and unloaded) are shown in Fig. 2A. As can be observed, all formulations ranged from $0.55 \pm 0.08$ to $0.93 \pm 0.05 \mathrm{~mm}$. These thickness values are adequate to avoid discomfort when applied, because an ideal buccal film should exhibit a thickness between 50 and $1000 \mu \mathrm{m}$ (Nair et al., 2013). No significant differences $(p>0.05)$ between the thickness of the different formulations were observed. Therefore, based on these results, the incorporation of the drug into the film, whether as a solid or as a solution, does not affect the thicknesses of the formulation. Regarding the folding endurance, all formulations loaded and unloaded with MN were folded at least 300 times without breaking, meeting the assay criteria (Avachat et al., 2013). This study was carried out to evaluate film flexibility, which is highly desirable in order to avoid easy dislocation from the site of application or film breaking during administration, and also to ensure that the film can be easily handled to produce comfort and a secured application (Avachat et al., 2013).

When tensile strength was analyzed (Fig. 2B) significant differences were found between loaded and non loaded $\mathrm{CH}$-carrageenans films $(p<0.001)$. The tensile strength values of $\mathrm{CH}$ unloaded films were significantly improved when $\mathrm{CH}$ was combined with carragenans $(p<0.05)$. In particular, tensile strength of $\mathrm{CH}-\lambda-\mathrm{C}$ films was the highest one, which could be due to the fact that $\lambda-C$ presents three ester
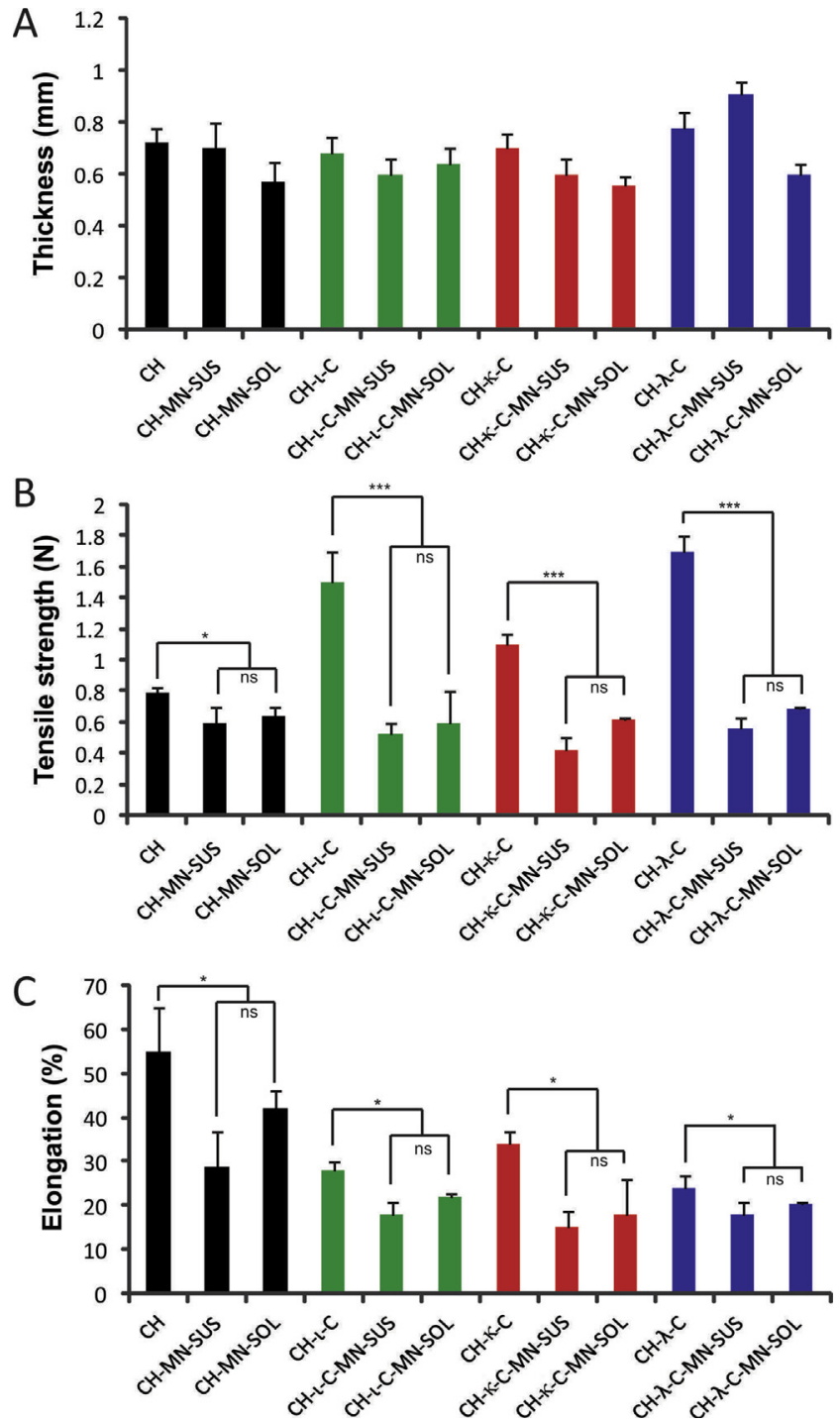

Fig. 2. Characterization of different films. A: Thickness, B: Tensile strength, C: Elongation at break. Each bar represents the mean value ( $n=10$ for thickness, $\mathrm{n}=3$ for tensile strength, $\mathrm{n}=3$ for elongation at break) and errors bars refer to standard deviation (SD). ${ }^{* * *} p<0.001,{ }^{*} p<0.05$, ns: $p>0.05$.

sulfate groups per galactose units, while $\mathrm{\kappa}$-C presents only one (Fig. 1). Thus, more anionic groups are available to interact with $\mathrm{CH}$ by ionic, electrostatic and/or hydrogen bonding, which may bring about the improvement in the tensile strength. On the other hand, no differences were found between films loaded with suspended or solubilized MN. However, a tendency can be observed, showing a lower tensile strength for the films loaded with suspended drug (Fig. 2B).

Formulations based only on $\mathrm{CH}$ were those that presented higher elongation at break values. The elongation at break of different formulations showed a similar tendency (Fig. 2C). Elasticity values were the highest for unloaded films followed by films loaded with solubilized MN and finally by those loaded with suspended drug.

The elongation of $\mathrm{CH}$ unloaded films decreased significantly when $\mathrm{CH}$ was in combination with the anionic polymers $(p<0.001)$, giving more rigid matrices. The elongation between the composited films was highest for the combination $\mathrm{CH}-\kappa-\mathrm{C}$ and decreased with the improvement of the negative charges per galactose units in the carragenan. Thus, the more available charges, the more interactions and the less elasticity.

Desired mechanical properties of buccal films will vary depending on the formulation goals and the applied procedure (Morales and 

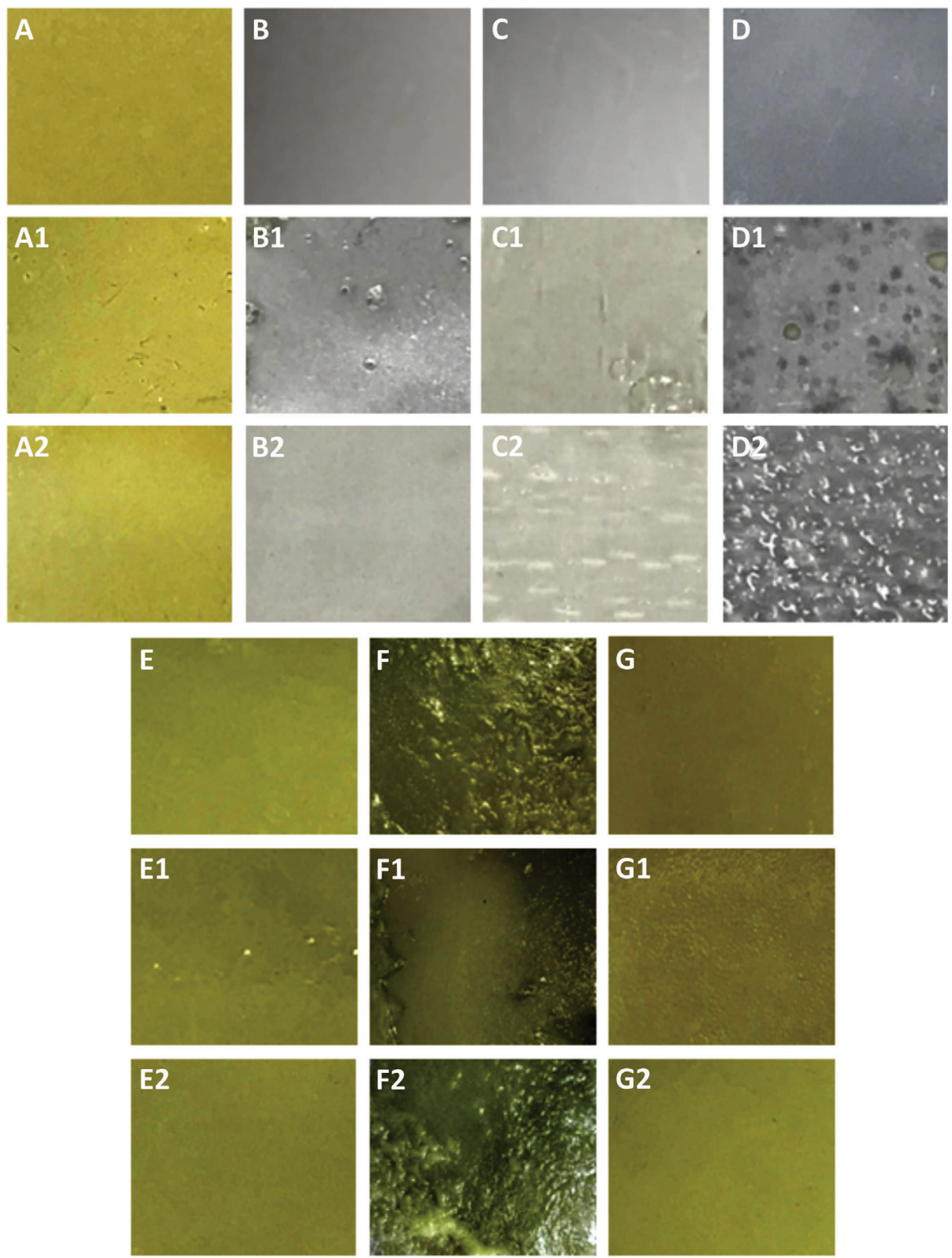

Fig. 3. Morphological surface of different films. A: CH, B: $\kappa-C$, C: $1-C, D: \lambda-C, A 1:$ CH-MN-SUS, B1: $\kappa-C-M N-S U S, ~ C 1: ~ 1-C-M N-S U S, ~ D 1: ~ \lambda-C-M N-S U S, A 2:$ CH-MN-SOL,

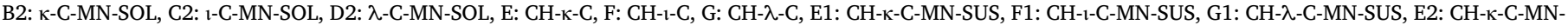
SOL, F2: CH-1-C-MN-SOL, G2: CH- $\lambda-$ C-MN-SOL.

McConville, 2011). An ideal buccal film should be flexible, elastic, soft but adequately strong to withstand breakage due to the stress of mouth activities (Szabó et al., 2013). Therefore, films displaying relatively high tensile strength and elongation at break are preferred for such application (Morales et al., 2013). In this work, as it was mentioned above, the elongation at break was reduced when $\mathrm{CH}$ was combined with carrageenans and even more when the number of anionic charges in carrageenans was increased (Fig. 1C) but this effect could probably be resolved increasing the plasticizer concentration in the films. Suyatma et al, analyzed the effect of the addition of $0,5,20$ and $40 \%$ $\mathrm{w} / \mathrm{w}$ of PEG 400 as plasticizers to $\mathrm{CH}$ films and found that the use of PEG $40 \% \mathrm{w} / \mathrm{w}$ produced the highest flexibility of $\mathrm{CH}$ films (Suyatma et al., 2005). On the other hand, it has also been reported that platicizer concentrations above a critical value can exceed the compatibility limit with biopolymers and produce a phase separation. Consequently, the plasticizer is excluded (Vieira et al., 2011) giving the idea that the plasticizer concentration could be increased but only up to certain limits to be compatible with the polymers.

The films based only on $\mathrm{CH}$ showed a smooth and homogeneous surface (Fig. 3A). A similar behavior was observed in films based on combinations CH-k-C (Fig. 3E) and CH- $\lambda$-C (Fig. 3G). On the other hand, $\mathrm{CH}-\mathrm{-}-\mathrm{C}$ films presented a shrink, irregular and non-uniform surface (Fig. 3F). This is probably due to the strong interactions between positive charges of $\mathrm{CH}$ and negative charges of the helical structures in $\mathrm{l}-\mathrm{C}$. Both $\mathrm{k}-\mathrm{C}$ and $\mathrm{t}-\mathrm{C}$ form a network of three-dimensional double helices, resulting from the crosslinking of the adjacent spiral chains that contain sulphate groups which are oriented towards their external part, and thus available to interact with $\mathrm{CH}$ (Campo et al., 2009). Probably, the numbers of sulphate groups (two per disaccharide) exposed, in the case of $1-\mathrm{C}$, produce stronger interactions with $\mathrm{CH}$ than in the case of $\kappa$ $\mathrm{C}$ (one per disaccharide). On the other hand, in $\lambda$-C, the sulphate groups are oriented towards the internal part, which could avoid the strong interactions with $\mathrm{CH}$ (Campo et al., 2009). Although the thickness, tensile strength, and elongation of films based on $\mathrm{CH}-\mathrm{-}-\mathrm{C}$ are in 


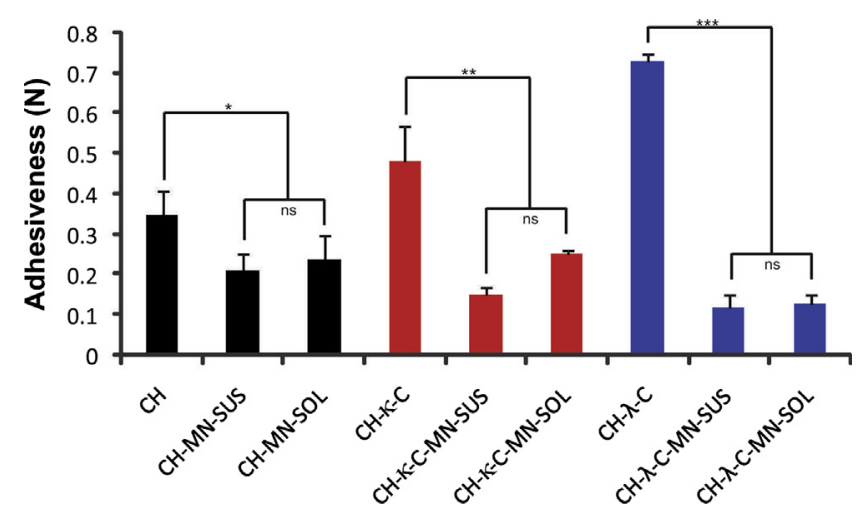

Fig. 4. Film mucoadhesive strength values. Each bar represents the mean value $(\mathrm{n}=3)$ and errors bars refer to SD. ${ }^{* * *} p<0.001,{ }^{* *} p<0.01,{ }^{*} p<0.05$, ns: $p>0.05$.

adequate range, their irregular and non-uniform surface shows some degree of non-homogeneous interactions between the polymers. This could generate irreproducible results, therefore, films based only on $\mathrm{CH}$ and combinations of $\mathrm{CH}-\kappa-\mathrm{C}$ and $\mathrm{CH}-\lambda-\mathrm{C}$ were selected for further analysis.

\subsection{In vitro mucoadhesive strength}

Film mucoadhesive strength values are shown in Fig. 4. The obtained mucoadhesive value for unloaded $\mathrm{CH}$ was $0.35 \mathrm{~N}$ similar to previously published values (Patel et al., 2007). As it was observed, unloaded combinations between oppositely charged films improved the mucoadhesion of $\mathrm{CH}(p<0.05)$. This could be due to the fact that more groups are present in the films to interact with the mucin, more often in the case of $\lambda$-C than in the case of $\kappa$-C. Thus, the formation of strong hydrogen bonds and ionic interactions between the polymer functional groups and the mucosa has a clear effect on the strength of mucoadhesion layer. Additionally, it has been reported that water interacts with polymer chains and softens the polymer matrix, allowing for entanglement of domains of mucin molecules and polymer chains (Morales et al., 2014). In the case of $\mathrm{CH}-\lambda-\mathrm{C}$, the matrices were more rigid (Fig. 2B); however, its high charge density might be the determining step in its mucoadhesive behavior. There are probably, more interactions with $\mathrm{CH}$, but also more free charges in these films to interact with the mucin. When MN was loaded, the mucoadhesive strength of films was decreased significantly. Similar results were reported by Naffe et al when MN was loaded in buccal patches based on different polymers such as sodium carboxymethyl cellulose, chitosan, polyvinyl alcohol, hydroxyethyl cellulose and hydroxypropylmethyl cellulose (Nafee et al., 2003). No differences were found between films loaded with solubilized and suspended MN; however, a tendency can be observed: films loaded with suspended MN showed slower adhesiveness. When MN was loaded (solubilized or suspended), no differences were found between the adhesiveness of the films. When $\mathrm{MN}$ is solubilized into the matrix, the charges of the polymers may interact with the drug, reducing the free available charges to attach to the gingival zone. On the other hand, when MN was suspended into the matrix, the crystals on the film surface probably reduce the superficial area with mucoadhesive capacity. As it can be observed in Fig. 4 mucoadhesive force values of loaded films ranged from $0.11 \mathrm{~N}$ to $0.25 \mathrm{~N}$ showing that these films posses moderated mucoadhesive properties (Morales and McConville, 2011). It is important to say that the mucoadhesive strength of the developed polymeric films could be improved by adding some polymers presenting high mucoadhesive properties such as Guar gum, Carbopol ${ }^{\circledR}$, Polycarbophil, Poly(ethylene oxide) or Sodium carboxymethyl cellulose (Morales and McConville, 2011) to the matrix in order to fulfill the requirements for an ideal buccal film.

\subsection{Swelling index}

Films swelled in different ways depending on the polymers used in the formulations and the presence of suspended or solubilized MN (Fig. 5). Films based only on $\mathrm{CH}$ disintegrated after $30 \mathrm{~min}$ (Fig. 5A). On the other hand, films based on polymers with opposite charge densities produced a low mass equilibrium and an important increase in the disintegration time. All formulations based on polymer combinations swelled for at least $24 \mathrm{~h}$ without undergoing disintegration. After $24 \mathrm{~h}$, the swelling index values were $0.71,0.77$ and 0.73 for $\mathrm{CH}-\lambda-\mathrm{C}, \mathrm{CH}-\lambda-\mathrm{C}-$ MN-SUS and CH- $\lambda$-C-MN-SOL, respectively, while for films $\mathrm{CH}-\kappa-\mathrm{C}, \mathrm{CH}-$

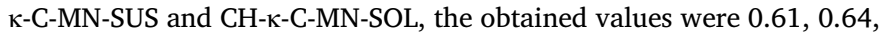
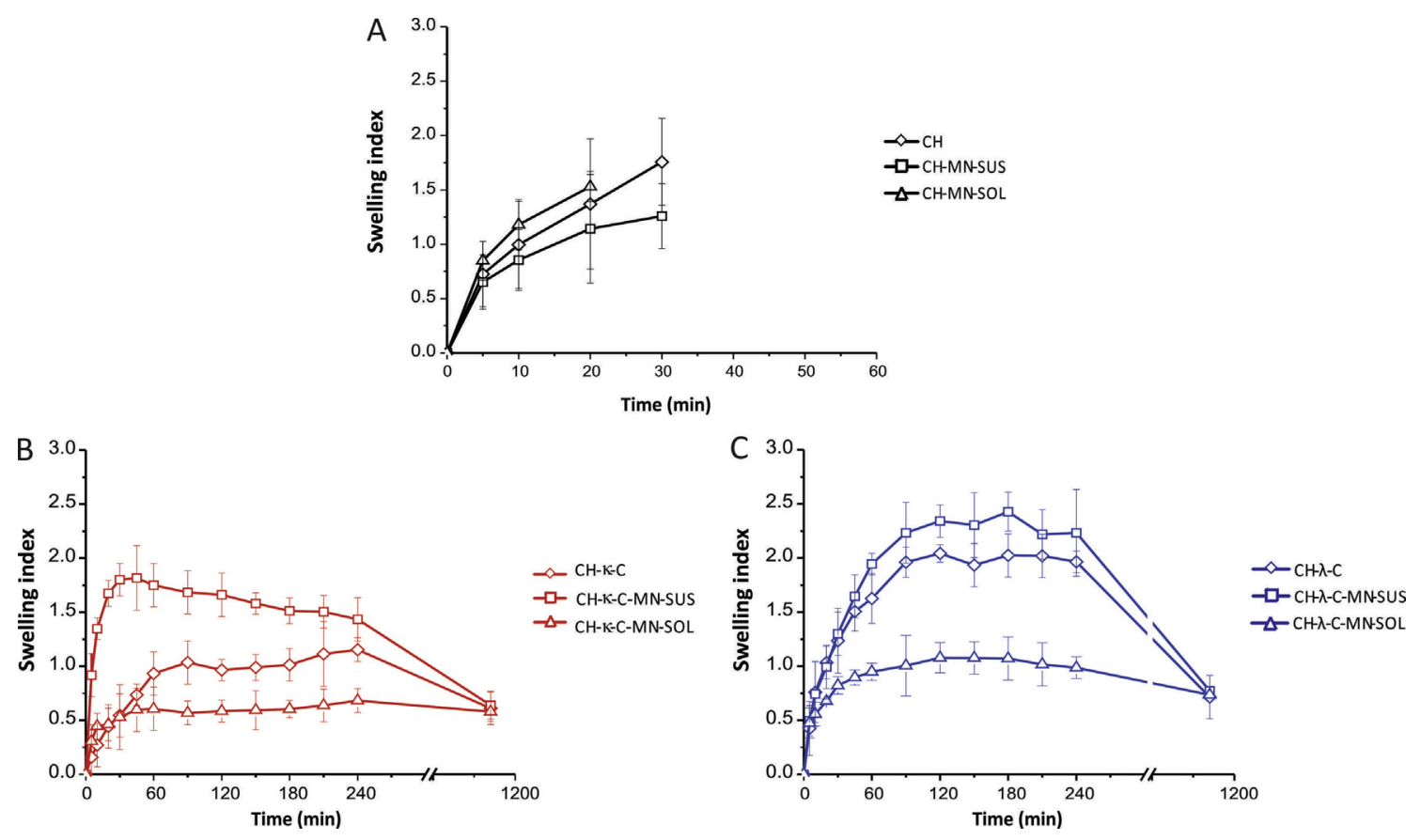

Fig. 5. Film swelling and disintegration in $0.5 \mathrm{~mL}$ of artificial saliva $(n=3 \pm S D)$. 


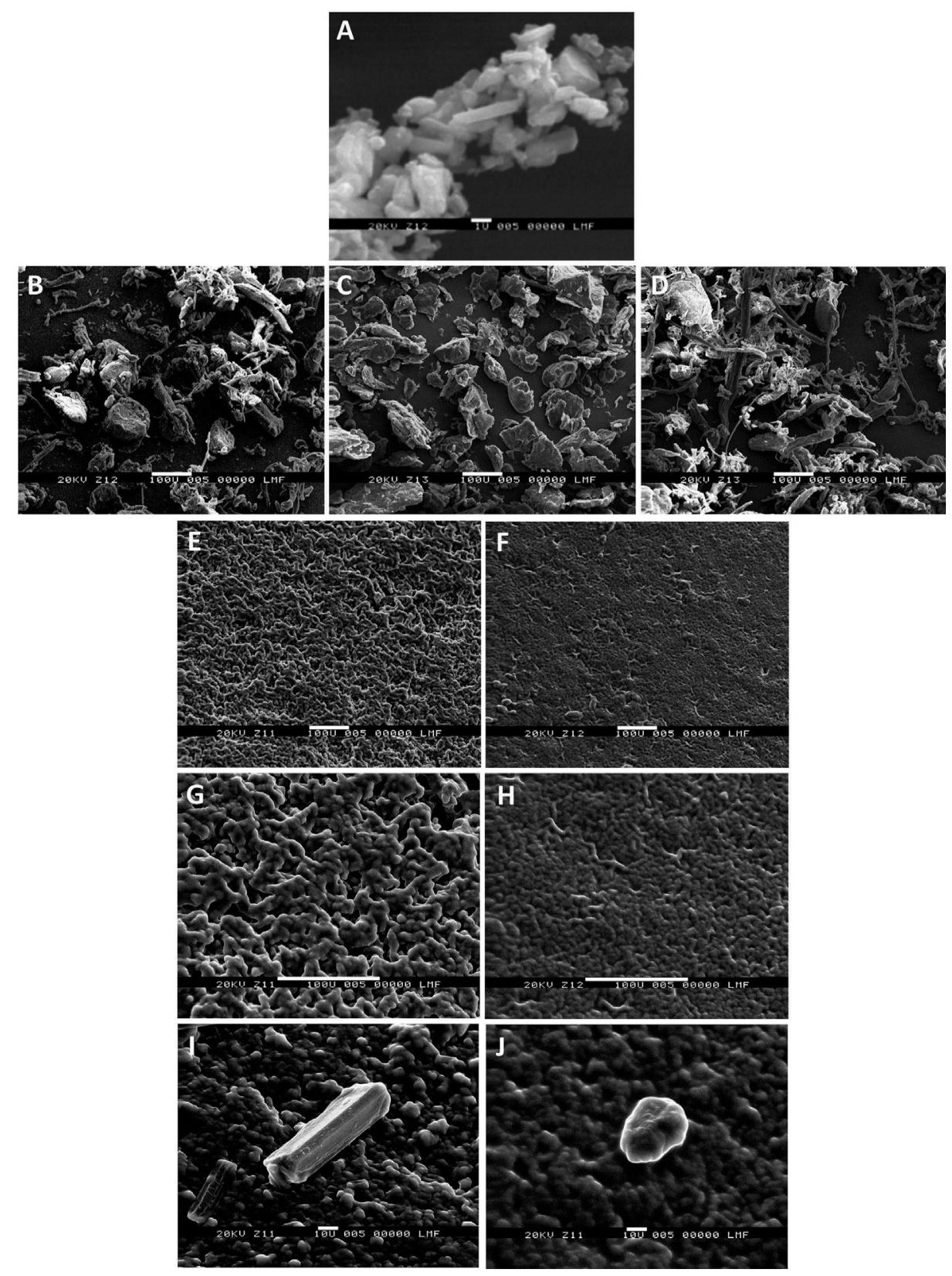

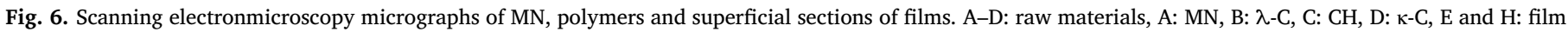

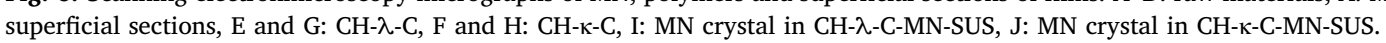

and 0.58. It may be postulated that ionic interactions between the molecules induced stronger non-covalent binding, leading to films which are less swellable and which present a better structure to be administered for buccal treatments. Among the different films, it can be observed that formulations containing $\lambda$-C showed higher swelling values than those containing $\kappa$-C. This could be explained by the higher number of charges present in $\lambda-C$, and the fact that the structural conformation of the films could be different. As mentioned before, $\kappa-\mathrm{C}$ forms a network of three-dimensional double helices which results from the crosslinking of the adjacent spiral chains that contain sulphate groups oriented towards their external part, and thus more available to interact with $\mathrm{CH}$ than sulphate groups present in $\lambda$-C (which are oriented towards the internal part, thus avoiding strong interactions). If so, although the interactions with $\mathrm{CH}$ produced more rigid matrices (as observed in Fig. 2), in the case of $\lambda$-C more charges are free to interact with artificial saliva, showing higher swelling degree. This result is consistent with that obtained in the mucoadhesion assay. Films loaded with suspended MN showed the highest swelling degree (even more than unloaded films). This is probably due to the fact that the presence of a particulate material disrupts the continuum of the polymeric matrix, allowing for more free space and increasing the matrix surface exposed to the solvent (Morales et al., 2014). In contrast, when films are loaded with solubilized MN, some of the charges of the matrixes could interact with the drug, reducing the number of free charges available to interact with the solvent, resulting in the lowest swelling values.

As mentioned before, films based only on $\mathrm{CH}$ showed the highest swelling degree and they were disintegrated between 30 and $40 \mathrm{~min}$ after starting the assay. $\mathrm{CH}$ can be categorized as superabsorbent and $\mathrm{CH}$ free groups play an important role in water uptake because of their hydrophilic nature (Karki et al., 2016). These kinds of matrices are not adequate for the aim of this work and, therefore, combinations of $\mathrm{CH}-\kappa-$ $\mathrm{C}$ and $\mathrm{CH}-\lambda-\mathrm{C}$ were selected for further analysis. 

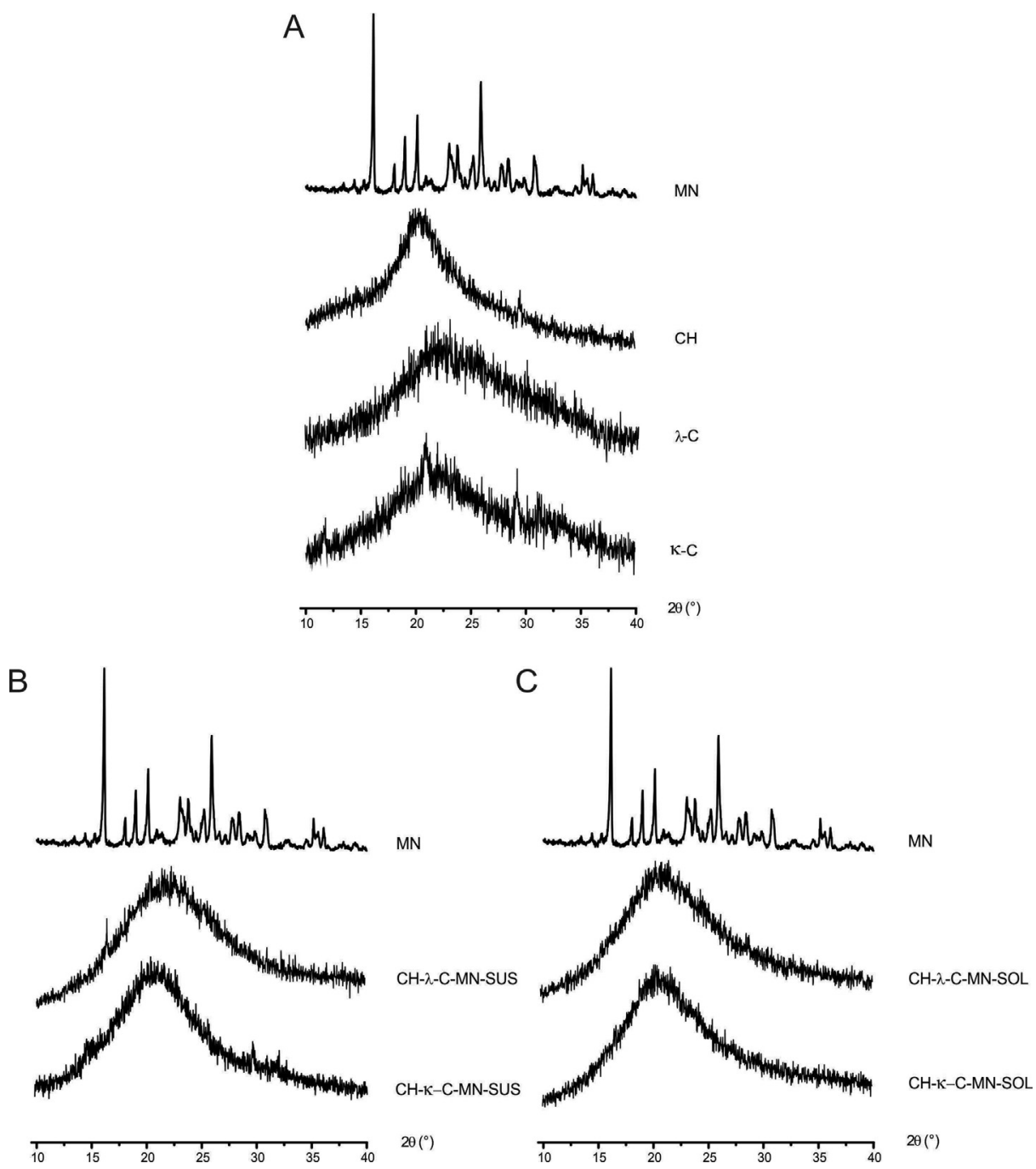

Fig. 7. X-ray diffraction patterns of MN raw material, polymers and films.

\subsection{Scanning electron microscopy}

The morphology of MN, $\mathrm{CH}, \kappa-\mathrm{C}, \lambda-\mathrm{C}$ and superficial surface of films based on polymer combinations are shown in Fig. 6. As observed, MN appears as irregular small crystals $(10-20 \mu \mathrm{m}$, Fig. 6A) while $\mathrm{CH}$ (Fig. 6C) are blocks $(100-300 \mu \mathrm{m})$ presenting a smooth surface with few smaller particles $(20-40 \mu \mathrm{m})$. Finally, $\kappa-\mathrm{C}$ (Fig. 6B) and $\lambda$-C (Fig. 6D) appear as irregular and fibrous blocks $(50-200 \mu \mathrm{m})$ with non-uniform surface. All films based on $\mathrm{CH}-\kappa-\mathrm{C}$ and $\mathrm{CH}-\lambda-\mathrm{C}$ were homogeneous, but showed a highly different surface. While the surface of films based on $\mathrm{CH}-\lambda-\mathrm{C}$ were slightly rough (Fig. $6 \mathrm{~F}$ and $6 \mathrm{H}$ ), those based on $\mathrm{CH}-\kappa-\mathrm{C}$ proved to be rough with a porous surface and presented a three-dimensional interconnected microstructure (Fig. 6E and 6G). The interconnection between pores could be assigned to the crosslinking network formation, probably due to the special conformation of $\kappa-\mathrm{C}$, exposing its sulphate groups oriented towards their external part, which could allow for strong but non-homogeneous interaction with $\mathrm{CH}$. Films based on $\mathrm{CH}-\lambda-\mathrm{C}$ showed a dense and compact structure, suggesting high structural integrity and adequate compatibility between the components (Villacrés et al., 2014).

When films were loaded with suspended MN, small crystals of the drug were identified in the film surface (Fig. 6I and J); while in the case of films loaded with solubilized MN, no crystals were observed.

\subsection{X-ray diffraction}

The X-ray study was carried out to characterize the state of MN in the films. The X-ray patterns of the MN raw material, polymers and films are shown in Fig. 7.

The MN spectra showed a typical crystalline pattern with sharp and

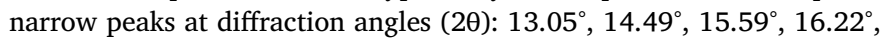
$18.55^{\circ}, 20.80^{\circ}, 21.57^{\circ}, 22.95^{\circ}, 25.19^{\circ}, 26.15^{\circ}, 27.32^{\circ}, 29.9^{\circ}, 31.82^{\circ}$, $33.12^{\circ}, 36.6^{\circ}$, and $40.69^{\circ}$. A peak at around $20^{\circ}$ related to the anhydrous $\mathrm{CH}$ crystals was observed in $\mathrm{CH}$ raw material (Li et al., 2009). Likewise, $\kappa$-C presented two crystalline peaks at $21^{\circ}$ and $29^{\circ}$. Finally $\lambda$-C showed an amorphous structure (Fig. 7A). Films did not show any clear peaks corresponding to crystalline MN (Fig. 7B and C); only a small peak was observed at $16.22^{\circ}$ which corresponds to the drug in $\mathrm{CH}-\lambda$-C-MN-SUS (Fig. 7B). The absence of peaks in the spectra of films could suggest that $\mathrm{MN}$ is in an amorphous state even in films where the drug was suspended, or that MN reduced partially its crystallinity during the film formulation, or that the MN concentration in the films is below the detection limit (Leuner and Dressman, 2000). Based on visual analysis (Fig. 3) and SEM studies, where several crystals were observed on $\mathrm{CH}$ $\lambda$-C-MN-SUS and CH-к-C-MN-SUS (Fig. 6I and J), the absence of peaks in the case of films loaded with suspended MN may be because either cristallinity has been partially reduced or the concentration of the drug in the film is below the detection limit.

On the other hand, in the case of films loaded with solubilized MN the drug could be in an amorphous state. In the X-ray spectra of films 

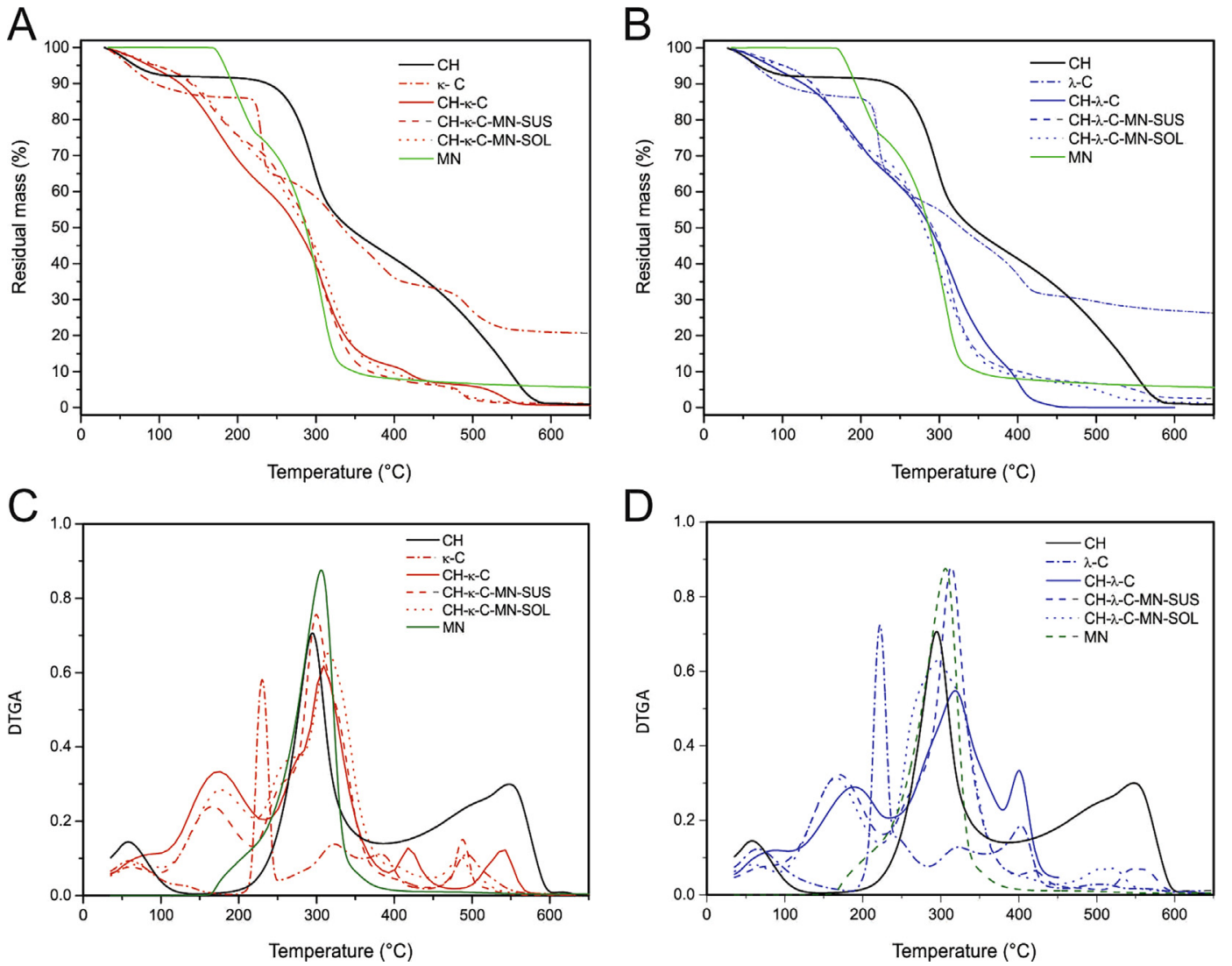

Fig. 8. TGA (A and C) and DTGA (B and D) curves. A and B: MN, polymers and CH- $\lambda-\mathrm{C}$ films, C and D: MN, polymers and CH- $-\mathrm{C}$ films.

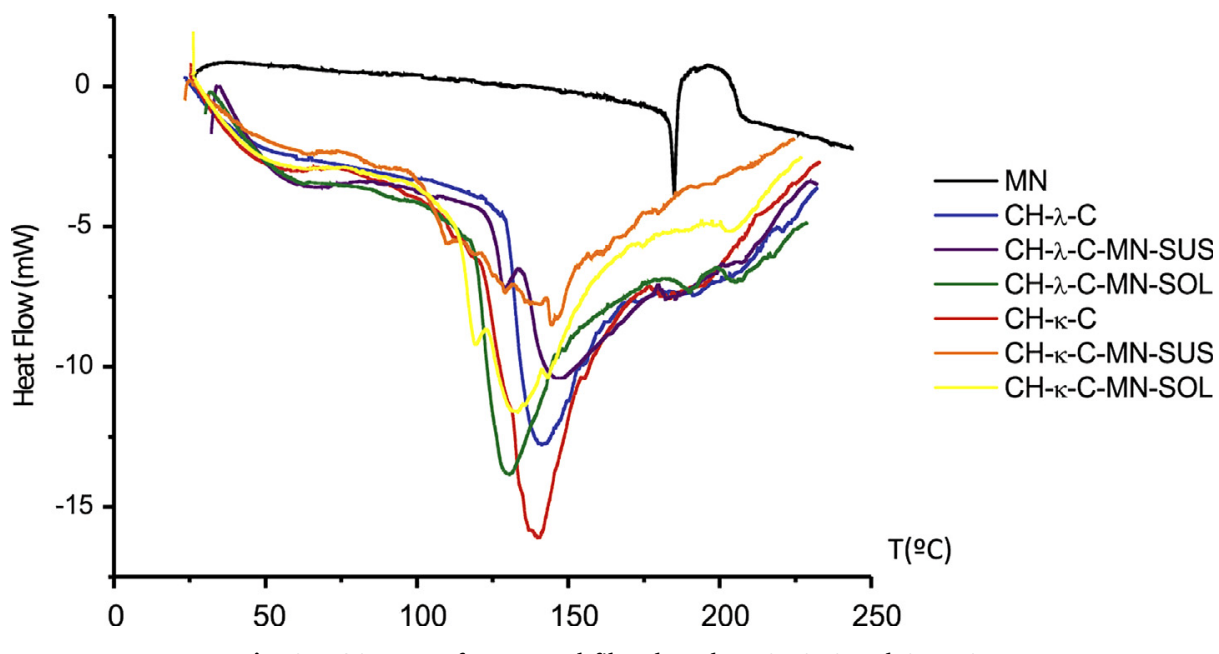

Fig. 9. DSC curves for $\mathrm{MN}$ and films based on $\mathrm{CH}-\lambda-\mathrm{C}$ and $\mathrm{CH}-\kappa-\mathrm{C}$.

based on oppositely charged polymers, the typical peak of $\mathrm{CH}$ disappeared, suggesting that the introduction of anionic polymers into $\mathrm{CH}$ disrupted its crystalline structure. It has been reported that amino and hydroxyl groups in $\mathrm{CH}$ form complexes with anionic polymers, which may break the hydrogen bonding between amino groups and hydroxyl groups in CH, resulting in an amorphous structure (Li et al., 2009). Similarly, in the case of $\mathrm{k}-\mathrm{C}$, its three-dimensional double helices resulting from the crosslinking of the adjacent spiral chains that contain sulphate groups externally-oriented could be disrupted by the presence of $\mathrm{CH}$, losing its crystalline structure.

\subsection{Thermal analysis}

Fig. 8 shows the TGA and DTGA curves of MN, polymers and selected films. From the curves, it is possible to observe that the $\mathrm{CH}$ polymer presents degradation in a single stage whose maximum degradation speed is centered at $297^{\circ} \mathrm{C}$, which corresponds to the depolymerization thereof (de Britto and Campana-Filho, 2004). A small peak can also be observed between 40 and $100^{\circ} \mathrm{C}$ that is related to the water absorbed and corresponds to the first mass drop in the TGA curve (de Britto and Campana-Filho, 2004). Both $\kappa-\mathrm{C}$ and $\lambda$-C exhibited similar degradation steps: the first one, centered at around $60{ }^{\circ} \mathrm{C}$ may correspond to the loss of adsorbed and bound water, the second and main one is centered at around $230{ }^{\circ} \mathrm{C}$, and two more at higher temperatures 


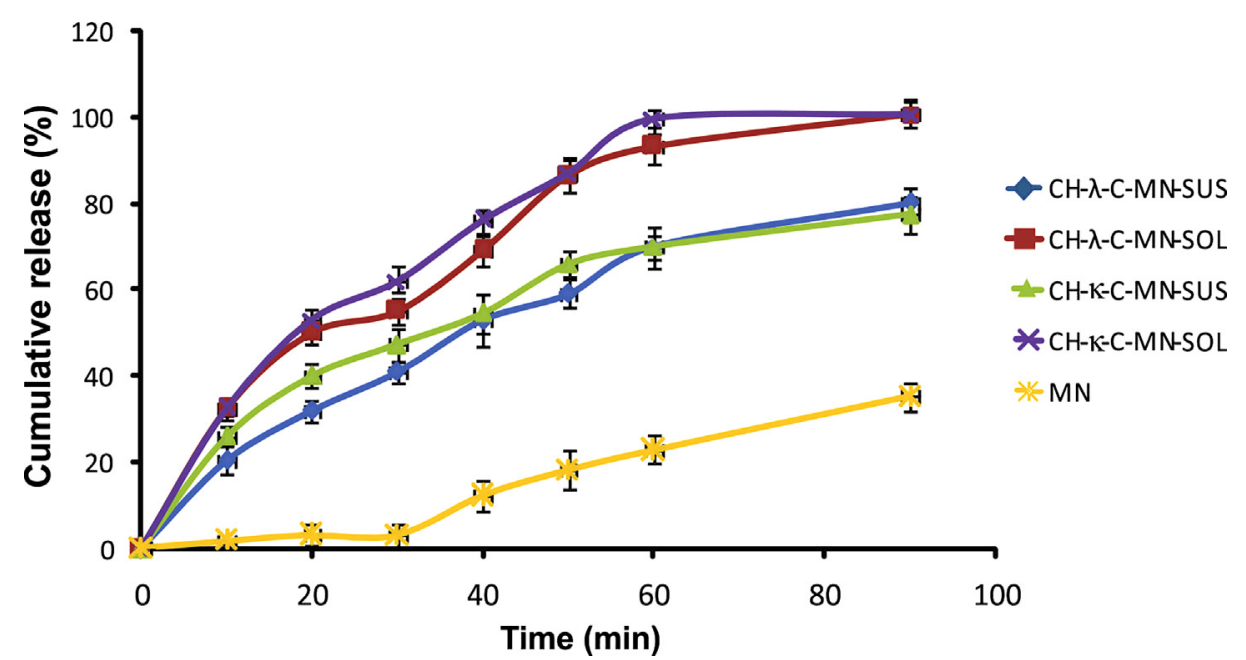

Fig. 10. Dissolution studies of $\mathrm{MN}$ raw material and films, performed in $900 \mathrm{~mL}$ of distilled water containing $1 \%$ PEG 400 at $37^{\circ} \mathrm{C}$ (n $=3 \pm$ SD).

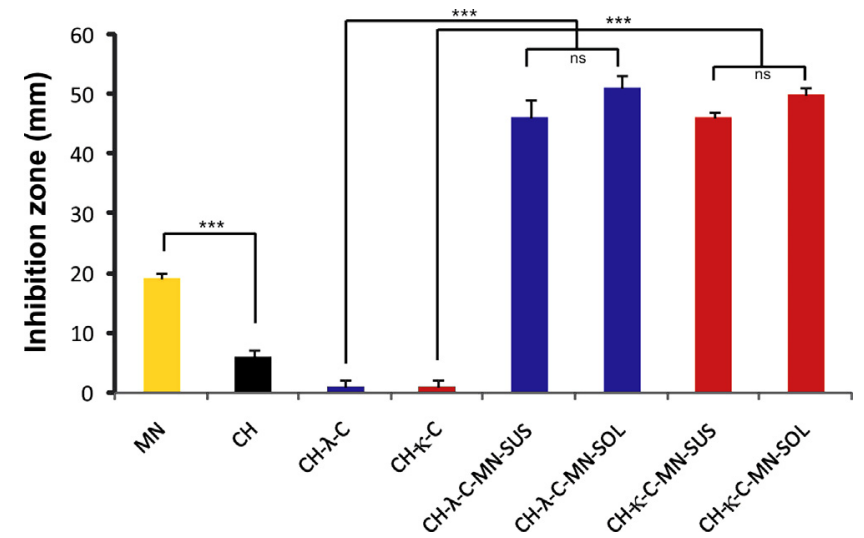

Fig. 11. Growth inhibition halos around the disc and comparison between the antifungal activities of $\mathrm{MN}$ raw material, $\mathrm{CH}$, and assayed films. Each bar represents the mean value $(\mathrm{n}=6)$ and errors bars refer to SD. ${ }^{* * *} p<0.001$, ns: $p>0.05$.

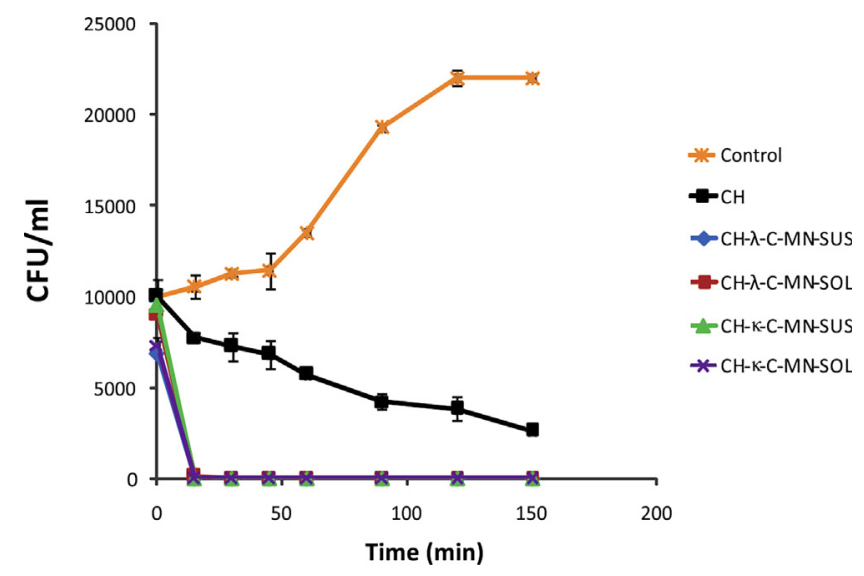

Fig. 12. Time-to-kill curves of $\mathrm{CH}$ and selected films $(n=3 \pm \mathrm{SD})$.

(320-400 ${ }^{\circ} \mathrm{C}$ ) (Rane et al., 2014; Sadeghi, 2012). On the other hand, the drug, MN, has a broad peak centered at $305^{\circ} \mathrm{C}$. In the case of the films without MN, four different steps can be recognized: 1) $60^{\circ} \mathrm{C}$ (water), 2) $185^{\circ} \mathrm{C}$ (associated with plasticizer), 3) $230^{\circ} \mathrm{C}$ (associated with carrageenan) and 4) $320^{\circ} \mathrm{C}$ (near to $\mathrm{CH}$ decomposition). The peaks at temperatures higher than $400^{\circ} \mathrm{C}$ could be associated with the decomposition of the original degradation products. When $\mathrm{MN}$ was incorporated to the films, the difference was related with the degradation temperature of the drug.

Fig. 9 shows the DSC curves for MN and films based on $\mathrm{CH}-\lambda-\mathrm{C}$ and $\mathrm{CH}$ - $\mathrm{\kappa}$-C. In the case of MN, whereas the first peak is associated with the melting of the drug, the second one can be related with the starting of the degradation. It is important to note that, in all cases, polymers act as a thermal protective on $\mathrm{MN}$, increasing the temperature of the last peak whereas no evidence of the melting point of the drug inside the films was present, in accordance with X-ray results. Again, in the case of films loaded with suspended MN the absence of the melting point of the drug is probably because MN partially reduced its crystallinity or because MN concentration in the films is below the detection limit, while in the case of films loaded with solubilized MN, the drug could be in amorphous state.

\subsection{Dissolution studies}

Films loaded with solubilized MN showed the fastest dissolution rate (Fig. 10). After $60 \mathrm{~min}$ assay, these films allowed the release of $100 \%$ of the drug, while those films loaded with suspended MN released $70 \%$ of drug, and only $20 \%$ of MN was released from MN raw material. No significant differences were found between matrices based on $\mathrm{\kappa}-\mathrm{C}$ and $\lambda-C(p>0.05)$.

The improvement in the dissolution rate of MN when it was suspended in the films is probably because polymeric matrices enhanced the wettability of the drug and also reduced drug agglomeration, increasing surface area and improving MN dissolution rate (Craig, 2002). On the other hand, films loaded with solubilized MN could improve the drug dissolution due to the fact that MN is in an amorphous state. As reported, the amorphous state of a drug leads to high-energy drug solid state resulting in enhanced solubility and dissolution rate (Jermain et al., 2018).

\subsection{Halo zone test}

A paper disk containing $\mathrm{MN}$ powder, and unloaded $\mathrm{CH}, \mathrm{CH}-\kappa-\mathrm{C}$ and $\mathrm{CH}-\lambda-\mathrm{C}$ films were designed as controls. MN raw material produced inhibition zones around $18 \mathrm{~mm}$ while unloaded films based only on $\mathrm{CH}$ showed hales around $6 \mathrm{~mm}$, which is in agreement with the reported antifungal activity of the polymer (Elsabee and Abdou, 2013). Also, unloaded $\mathrm{CH}-\kappa-\mathrm{C}$ and $\mathrm{CH}-\lambda-\mathrm{C}$ films produced smaller growth inhibition zones around $1.5 \mathrm{~mm}$ which are probably due to the presence of $\mathrm{CH}$ in the formulations (Fig. 11). As regards the loaded films, no significant differences $(p>0.05)$ were found between films loaded with solubilized or suspended MN as all formulations showed similar halos 
between 40 and $50 \mathrm{~mm}$. However, a tendency can be observed in Fig. 11: all films loaded with solubilized MN presented, in average, higher inhibition zones than films loaded with suspended MN. On the other hand, significant differences $(p<0.001)$ were found between loaded formulations and MN powder. Thus, it can be postulated that films were able to inhibit $C$. albicans growth by the combination of two factors: the MN released from the formulations and the antimicrobial properties of $\mathrm{CH}$. Probably, MN raw material, a hydrophobic drug, was unable to dissolve in the culture medium and therefore its dissolution/ diffusion performance was incomplete, producing smaller inhibitionhalos than films.

As observed in Fig. 10, the dissolution of films loaded with solubilized MN was faster than those loaded with the suspended one. Therefore, it was expected that more dissolution/diffusion in C. albicans cultures medium will produce higher halos of inhibition. However, as mentioned, the inhibition halos produced by films loaded with suspended or solubilized MN did not show significant differences. This fact is probably related to the employed methodology that requires the placement of films onto the surface of agar followed by air-incubation at $28^{\circ} \mathrm{C}$ for $24 \mathrm{~h}$ before the halo zone is read. It could be postulated that during incubation both, suspended and solubilized MN, are able to spread reaching the same inhibition hale.

\subsection{Time-to-kill analysis}

Fig. 12 shows the time-to-kill profiles of $\mathrm{CH}$ and the selected films loaded with MN. It was observed that the control curve showed an increase in the number of colony forming units compared with the initial inoculum. On the other hand, after $150 \mathrm{~min} \mathrm{CH}$ polymer produced a reduction of the $C$. albicans culture (from $10,000 \mathrm{CFU} / \mathrm{mL}$ to $2500 \mathrm{CFU} / \mathrm{mL}$ ). It has been reported that low concentrations of $\mathrm{CH}$ produces a series of alterations of ion homeostasis and metabolism of the yeast while at high concentrations it may act as permeation agent for bacteria and fungi (Peña et al., 2013). Thus, when $\mathrm{CH}$ is used at concentrations higher than $1.0 \mathrm{mg} / \mathrm{mL}$ not only a fungistatic but also a fungicidal activity is observed. In this assay the $\mathrm{CH}$ concentration (when placing unloaded films into the medium) was $0.6 \mathrm{mg} / \mathrm{mL}$, therefore, the polymer presented fungistatic activity. All formulations containing the drug allowed a complete eradication of the $C$. albicans culture after $15 \mathrm{~min}$ assay. Almost super imposable profiles were obtained for $\mathrm{CH}-\kappa-\mathrm{C}$ and $\mathrm{CH}-\lambda-\mathrm{C}$ with suspended or solubilized MN. The minimum inhibitory concentration (MIC) and the minimum fungicidal concentration (MFC) using MN for oropharyngeal C. albicans strains were found to be $3.9 \mu \mathrm{g} / \mathrm{mL}$ and $13.7 \mu \mathrm{g} / \mathrm{mL}$ respectively (D'auria et al., 2005). It was observed that both kinds of films (loaded with suspended or solubilized MN) allowed to reach the fungicidal MN concentration at 15 min assay and, as consequence, no colony forming units were observed after this time. This result shows that the antinfungal activity of these formulations is not modified when the drug is loaded either suspended or solubilized into de matrix.

\section{Conclusions}

In this work, mucoadhesive buccal films based on $\mathrm{CH}$ and carrageenans were successfully developed and characterized. Films based on $\mathrm{CH}-\kappa-\mathrm{C}$ and $\mathrm{CH}-\lambda-\mathrm{C}$ combinations, showed a thermal protective effect on the drug, presented homogeneous surface, high tensile strength, moderated elongation at break and adhesiveness, and were able to swell during $24 \mathrm{~h}$ without suffering disintegration. It was observed that the combination of $\mathrm{CH}$ and $\lambda$-C led to films with the highest tensile and mucoadhesive strength values, and presented the highest swelling. These facts are probably because some of the sulfate groups of $\lambda-C$ interact with $\mathrm{CH}$ while others are free in the matrices; the latter groups could interact with mucin and artificial saliva. Regarding the incorporation of suspended or solubilized MN into the polymeric films at the concentration selected did not produce significant changes in the mechanical behavior of the prepared polymer-based films. It can be concluded from obtained results that no significant differences were detected in the mechanical behavior between suspended and solubilized MN in polymer-based films. However, a tendency was observed: films with solubilized MN displayed slightly higher tensile strength, elongation at break and mucoadhesive strength than those with suspended MN. On the other hand, swelling was slightly improved when the drug was suspended, probably because particulate material, observed by SEM, disrupts the continuity of the polymeric matrix, allowing more free space increasing the surface of the matrix exposed to the solvent. DRX and thermal analysis were unable to detect the MN, probably due to the fact that in films loaded with suspended MN, the drug partially reduced its crystallinity below the detection limit, while in the case of films loaded with solubilized MN, the drug could be in an amorphous state. Drug release was faster when MN was solubilized in the matrix, probably because the amorphous state of the drug leads to a high-energy solid state, resulting in enhanced dissolution rate. However, no differences were found regarding the antifungal activity of the different formulations even when analyzing time-to-kill curves.

\section{Acknowledgements}

The authors gratefully acknowledge the Universidad Nacional de Rosario (BIO 509) and CONICET Argentina for financial support. We would like to thank the staff from the English Department (Facultad de Ciencias Bioquímicas y Farmacéuticas, Universidad Nacional de Rosario) for their assistance in the language correction of the manuscript.

\section{References}

Avachat, A.M., Gujar, K.N., Wagh, K.V., 2013. Development and evaluation of tamarind seed xyloglucan-based mucoadhesive buccal films of rizatriptan benzoate. Carbohydr. Polym. 91, 537-542.

Borges, A.F., Silva, C., Coelho, J.F., Simões, S., 2015. Oral films: current status and future perspectives: I—galenical development and quality attributes. J. Control. Release 206, 1-19.

Campo, V.L., Kawano, D.F., da Silva Jr, D.B., Carvalho, I., 2009. Carrageenans: biological properties, chemical modifications and structural analysis - a review. Carbohydr. Polym. 77, 167-180.

Clinical and Laboratory Standards Institute, W. PA., 2008. Method for antifungal disk diffusion susceptibility testing of yeasts. Approved guideline. Second edition. Approved guideline. Second edition. Document M44-A2.

Craig, D.Q., 2002. The mechanisms of drug release from solid dispersions in water-soluble polymers. Int. J. Pharm. 231, 131-144.

Cha, D.S., Choi, J.H., Chinnan, M.S., Park, H.J., 2002. Antimicrobial films based on Naalginate and א-carrageenan. LWT-Food Sci. Technol. 35, 715-719.

Chonkar, A.D., Rao, J.V., Managuli, R.S., Mutalik, S., Dengale, S., Jain, P., Udupa, N., 2016. Development of fast dissolving oral films containing lercanidipine $\mathrm{HCl}$ nanoparticles in semicrystalline polymeric matrix for enhanced dissolution and ex vivo permeation. Eur. J. Pharm. Biopharm. 103, 179-191.

D'auria, F., Tecca, M., Strippoli, V., Salvatore, G., Battinelli, L., Mazzanti, G., 2005. Antifungal activity of Lavandula angustifolia essential oil against Candida albicans yeast and mycelial form. Med. Mycol. 43, 391-396.

de Britto, D., Campana-Filho, S.P., 2004. A kinetic study on the thermal degradation of N, N, N-trimethylchitosan. Polym. Degrad. Stab. 84, 353-361.

Dixit, R., Puthli, S., 2009. Oral strip technology: overview and future potential. J. Control. Release 139, 94-107.

El-Kamel, A.H., Ashri, L.Y., Alsarra, I.A., 2007. Micromatricial metronidazole benzoate film as a local mucoadhesive delivery system for treatment of periodontal diseases. AAPS Pharm. Sci. Tech. 8, E184-E194.

Elsabee, M.Z., Abdou, E.S., 2013. Chitosan based edible films and coatings: a review. Mater. Sci. Eng., C 33, 1819-1841.

Eouani, C., Piccerelle, P., Prinderre, P., Bourret, E., Joachim, J., 2001. In-vitro comparative study of buccal mucoadhesive performance of different polymeric films. Eur. J. Pharm. Biopharm. 52, 45-55.

Gallagher, K., Corrigan, O., 2000. Mechanistic aspects of the release of levamisole hydrochloride from biodegradable polymers. J. Control. Release 69, 261-272.

Giovino, C., Ayensu, I., Tetteh, J., Boateng, J.S., 2013. An integrated buccal delivery system combining chitosan films impregnated with peptide loaded PEG-b-PLA nanoparticles. Colloids Surf B 112, 9-15.

Hambleton, A., Fabra, M.-J., Debeaufort, F., Dury-Brun, C., Voilley, A., 2009. Interface and aroma barrier properties of iota-carrageenan emulsion-based films used for encapsulation of active food compounds. J. Food Eng. 93, 80-88.

Jermain, S.V., Brough, C., Williams, R.O., 2018. Amorphous solid dispersions and nanocrystal technologies for poorly water-soluble drug delivery - an update. Int. J. 
Pharm. 535, 379-392.

A. Kalsoom Khan A.U. Saba S. Nawazish F. Akhtar R. Rashid S. Mir B. Nasir F. Iqbal S. Afzal F. Pervaiz 2017 Carrageenan based bionanocomposites as drug delivery tool with special emphasis on the influence of ferromagnetic nanoparticles Oxidative Med. Cell. Longev. 2017.

Karbowiak, T., Debeaufort, F., Champion, D., Voilley, A., 2006. Wetting properties at the surface of iota-carrageenan-based edible films. J. Colloid Interface Sci. 294, 400-410.

Karki, S., Kim, H., Na, S.-J., Shin, D., Jo, K., Lee, J., 2016. Thin films as an emerging platform for drug delivery. Asian J. Pharm. Sci. 11, 559-574.

Kaur, A., Kaur, G., 2012. Mucoadhesive buccal patches based on interpolymer complexes of chitosan-pectin for delivery of carvedilol. Saudi Pharm. J. 20, 21-27.

Khajuria, D.K., Patil, O.N., Karasik, D., Razdan, R., 2018. Development and evaluation of novel biodegradable chitosan based metformin intrapocket dental film for the management of periodontitis and alveolar bone loss in a rat model. Arch. Oral Biol. 85, 120-129.

Kianfar, F., Chowdhry, B.Z., Antonijevic, M.D., Boateng, J.S., 2012. Novel films for drug delivery via the buccal mucosa using model soluble and insoluble drugs. Drug Dev. Ind. Pharm. 38, 1207-1220.

Kolakovic, R., Peltonen, L., Laukkanen, A., Hirvonen, J., Laaksonen, T., 2012. Nanofibrillar cellulose films for controlled drug delivery. Eur. J. Pharm. Biopharm. 82, 308-315.

Krampe, R., Sieber, D., Pein-Hackelbusch, M., Breitkreutz, J., 2016. A new biorelevant dissolution method for orodispersible films. Eur. J. Pharm. Biopharm. 98, 20-25.

Leuner, C., Dressman, J., 2000. Improving drug solubility for oral delivery using solid dispersions. Eur. J. Pharm. Biopharm. 50, 47-60.

Li, X., Xie, H., Lin, J., Xie, W., Ma, X., 2009. Characterization and biodegradation of chitosan-alginate polyelectrolyte complexes. Polym. Degrad. Stab. 94, 1-6.

Libio, I.C., Demori, R., Ferrão, M.F., Lionzo, M.I.Z., da Silveira, N.P., 2016. Films based on neutralized chitosan citrate as innovative composition for cosmetic application. Mater. Sci. Eng. C Mater. Biol. Appl. 67, 115-124.

Lima, P.H., Pereira, S.V., Rabello, R.B., Rodriguez-Castellón, E., Beppu, M.M., Chevallier, P., Mantovani, D., Vieira, R.S., 2013. Blood protein adsorption on sulfonated chitosan and $\kappa$-carrageenan films. Colloids Surf. B Biointerfaces 111, 719-725.

Llabot, J., Palma, S., Manzo, R., Allemandi, D., 2007. Design of novel antifungal mucoadhesive films: Part I. Pre-formulation studies. Int. J. Pharm. 330, 54-60.

Montenegro-Nicolini, M., Morales, J.O., 2017. Overview and future potential of buccal mucoadhesive films as drug delivery systems for biologics. AAPS Pharm. Sci. Tech. 18, 3-14.

Morales, J.O., Brayden, D.J., 2017. Buccal delivery of small molecules and biologics: of mucoadhesive polymers, films, and nanoparticles. Curr. Opin. Pharmacol. 36, 22-28.

Morales, J.O., Huang, S., Williams, R.O., McConville, J.T., 2014. Films loaded with insulin-coated nanoparticles (ICNP) as potential platforms for peptide buccal delivery. Colloids Surf. B Biointerfaces 122, 38-45.

Morales, J.O., McConville, J.T., 2011. Manufacture and characterization of mucoadhesive buccal films. Eur. J. Pharm. Biopharm. 77, 187-199.

Morales, J.O., Su, R., McConville, J.T., 2013. The influence of recrystallized caffeine on water-swellable polymethacrylate mucoadhesive buccal films. AAPS Pharm. Sci. Tech. 14, 475-484.

Nafee, N.A., Ismail, F.A., Boraie, N.A., Mortada, L.M., 2003. Mucoadhesive buccal patches of miconazole nitrate: in vitro/in vivo performance and effect of ageing. Int. J. Pharm. 264, 1-14.

Nair, A.B., Kumria, R., Harsha, S., Attimarad, M., Al-Dhubiab, B.E., Alhaider, I.A., 2013. In vitro techniques to evaluate buccal films. J. Control. Release 166, 10-21.

Park, S.Y., Lee, B.I., Jung, S.T., Park, H.J., 2001. Biopolymer composite films based on кcarrageenan and chitosan. Mater. Res. Bull. 36, 511-519.

Patel, V.M., Prajapati, B.G., Patel, M.M., 2007. Design and characterization of chitosancontaining mucoadhesive buccal patches of propranolol hydrochloride. Acta Pharm. 57, 61-72.

Peh, K.K., Wong, C.F., 1999. Polymeric films as vehicle for buccal delivery: swelling, mechanical, and bioadhesive properties. J. Pharm. Pharm. Sci. 2, 53-61.

Peña, A., Sánchez, N.S., Calahorra, M., 2013. Effects of chitosan on Candida albicans: conditions for its antifungal activity. BioMed Res. Int.
Perugini, P., Genta, I., Conti, B., Modena, T., Pavanetto, F., 2003. Periodontal delivery of ipriflavone: new chitosan/PLGA film delivery system for a lipophilic drug. Int. J. Pharm. 252, 1-9.

Postigo, A., Funes, M., Petenatti, E., Bottai, H., Pacciaroni, A., Sortino, M., 2017. Antifungal photosensitive activity of Porophyllum obscurum (Spreng.) DC.: correlation of the chemical composition of the hexane extract with the bioactivity. Photodiagnosis Photodyn. Therapy 20, 263-272.

Rane, L.R., Savadekar, N.R., Kadam, P.G., Mhaske, S.T., 2014. Preparation and characterization of K-carrageenan/nanosilica biocomposite film. J. Mater.

Real, D.A., Martinez, M.V., Frattini, A., Soazo, M., Luque, A.G., Biasoli, M.S., Salomon, C.J., Olivieri, A.C., Leonardi, D., 2013. Design, characterization, and in vitro evaluation of antifungal polymeric films. AAPS Pharm. Sci. Tech. 14, 64-73.

Sadeghi, M., 2012. Synthesis of a biocopolymer carrageenan-g-poly (AAm-co-IA)/montmorilonite superabsorbent hydrogel composite. Braz. J. Chem. Eng. 29, 295-305.

Shahbazi, M., Rajabzadeh, G., Ettelaie, R., Rafe, A., 2016. Kinetic study of к-carrageenan degradation and its impact on mechanical and structural properties of chitosan/Кcarrageenan film. Carbohydr. Polym. 142, 167-176.

Sievens-Figueroa, L., Bhakay, A., Jerez-Rozo, J.I., Pandya, N., Romañach, R.J., MichniakKohn, B., Iqbal, Z., Bilgili, E., Davé, R.N., 2012. Preparation and characterization of hydroxypropyl methyl cellulose films containing stable BCS Class II drug nanoparticles for pharmaceutical applications. Int. J. Pharm. 423, 496-508.

Spampinato, C., Leonardi, D., 2013. Candida infections, causes, targets, and resistance mechanisms: traditional and alternative antifungal agents. BioMed Res. Int.

Suyatma, N.E., Tighzert, L., Copinet, A., Coma, V., 2005. Effects of hydrophilic plasticizers on mechanical, thermal, and surface properties of chitosan films. J. Agric. Food. Chem. 53, 3950-3957.

Szabó, B., Sebe, I., Kállai, N., Süvegh, K., Zelkó, R., 2013. Comparison of the micro-and macrostructural characteristics of biopolymer cast films. Eur. Polym. J. 49, 2422-2425.

Tang, C., Guan, Y.-X., Yao, S.-J., Zhu, Z.-Q., 2014. Preparation of ibuprofen-loaded chitosan films for oral mucosal drug delivery using supercritical solution impregnation. Int. J. Pharm. 473, 434-441.

Tejada, G., Barrera, M., Piccirilli, G., Sortino, M., Frattini, A., Salomón, C., Lamas, M.C., Leonardi, D., 2017. Development and evaluation of buccal films based on chitosan for the potential treatment of oral candidiasis. AAPS Pharm. Sci. Tech. 18, 936-946.

Tonglairoum, P., Ngawhirunpat, T., Rojanarata, T., Kaomongkolgit, R., Opanasopit, P., 2015a. Fabrication of a novel scaffold of clotrimazole-microemulsion-containing nanofibers using an electrospinning process for oral candidiasis applications. Colloids Surf. B Biointerfaces 126, 18-25.

Tonglairoum, P., Ngawhirunpat, T., Rojanarata, T., Panomsuk, S., Kaomongkolgit, R., Opanasopit, P., 2015b. Fabrication of mucoadhesive chitosan coated polyvinylpyrrolidone/cyclodextrin/clotrimazole sandwich patches for oral candidiasis. Carbohydr. Polym. 132, 173-179.

Trastullo, R., Abruzzo, A., Saladini, B., Gallucci, M.C., Cerchiara, T., Luppi, B., Bigucci, F., 2016. Design and evaluation of buccal films as paediatric dosage form for transmucosal delivery of ondansetron. Eur. J. Pharm. Biopharm. 105, 115-121.

Van Roey, J., Haxaire, M., Kamya, M., Lwanga, I., Katabira, E., 2004. Comparative efficacy of topical therapy with a slow-release mucoadhesive buccal tablet containing miconazole nitrate versus systemic therapy with ketoconazole in HIV-positive patients with oropharyngeal candidiasis. JAIDS 35, 144-150.

Vieira, M.G.A., da Silva, M.A., dos Santos, L.O., Beppu, M.M., 2011. Natural-based plasticizers and biopolymer films: a review. Eur. Polym. J. 47, 254-263.

Villacrés, R.A.E., Flores, S.K., Gerschenson, L.N., 2014. Biopolymeric antimicrobial films: study of the influence of hydroxypropyl methylcellulose, tapioca starch and glycerol contents on physical properties. Mater. Sci. Eng., C 36, 108-117.

Wang, Y., Guo, X., Pan, R., Han, D., Chen, T., Geng, Z., Xiong, Y., Chen, Y., 2015. Electrodeposition of chitosan/gelatin/nanosilver: a new method for constructing biopolymer/nanoparticle composite films with conductivity and antibacterial activity. Sci. Eng. C Mater. Biol. Appl. 53, 222-228.

Woertz, C., Kleinebudde, P., 2015. Development of orodispersible polymer films with focus on the solid state characterization of crystalline loperamide. Eur. J. Pharm. Biopharm. 94, 52-63. 